\title{
Using stochastic resonance and strength training as part of a rehabilitation programme for recurrent low back pain treatment: a case study
}

\author{
Jad Adrian Washifl'*, Jorg Teichmann², Lian-Yee Kok³, Dietmar Schmidtbleicher ${ }^{4}$ \\ ${ }^{1}$ Sports Performance Division, National Sports Institute, Kuala Lumpur, Malaysia \\ ${ }^{2}$ Sports Medicine Division, National Sports Institute, Kuala Lumpur, Malaysia \\ ${ }^{3}$ Department of Sport Studies, Universiti Putra Malaysia, Serdang, Malaysia \\ ${ }^{4}$ Department of Sport Science, Johann Wolfgang Goethe University, Frankfurt, Germany
}

Low back pain (LBP) is a common disabling health problem that can cause decreased spine proprioception. Stochastic resonance (SR) can influence detection performance, besides improving patients with significant sensory deficits, but have not been thoroughly tested for LBP. This study aimed to examine the application of SR therapy (SRT) and strength training for LBP treatment. The subject was a resistancetrained male in his early thirties. His back pain was unbearable after a strength training session. Standard pain relief alleviated the pain but the LBP developed at a similar intensity after 4 weeks. SRT (4-5 sets $\times 90$ sec, 30 -sec rest interval, supine position) was prescribed along with other exercises for 3 weeks (phase 1), and followed by tailor-made strength training for 16 weeks (phase 2). The Oswestry Disability Index was $66.7 \%$ (interpreted as "crippled") prior to first SRT, and reduced to minimal levels of $15.6 \%$ and $6.7 \%$ after four and seven SRT sessions, respectively. Similarly, pain intensity was ranging from 5 to 9 (distractingsevere) of the Numeric Rating Scale (NRS-11) prior to the first session but this was reduced considerably after four sessions (NRS-11: 0-1). During phase 2 , the patient performed without complaining of LBP, two repetitions of bench press exercise at a load intensity of 1.2 his body weight and attained 4 min of plank stabilisation. This LBP management strategy has a clinically meaningful effect on pain intensity, disability, and functional mobility, by receding the recurrent distracting to severe LBP.

Keywords: Back pain, Muscular strength, Sensory neuron, Stabilisation

\section{INTRODUCTION}

Low back pain (LBP) can cause a more global disability than any other condition. For example, LBP led to a considerable amount of 'time missed,' activity limitation, work absence, and disability throughout the world (Hoy et al., 2014; Lidgren, 2003; Petering and Webb, 2011). It has been estimated that at least $80 \%$ of individuals have experienced LBP in their lifetime (Hoy et al., 2010). Age is one most prevalent factors of LBP, but this phenomenon has also become increasingly common in the adolescent population (Hoy et al., 2010). Other factors that seem to have contributed to LBP are educational status, psychosocial factors, job satisfac- tion, type of occupation, and obesity (Hoy et al., 2010). Furthermore, LBP could also be influenced by psychological factors, such as stress, depression, and anxiety (Allegri et al., 2016).

The majority of diagnoses of acute back pain are non-specific, or without a clear specific cause, but the central symptoms of LBP are pain and disability (Koes et al., 2006). Conversely, hernia, arthritis, and fracture are among the known specific pathophysiological causes of specific LBP (Koes et al., 2006). Regardless of the above, numerous studies investigating the treatment modalities for LBP therapy have failed to determine an optimal strategy, but patients are recommended to be active and to restrict bed rest (Deyo et al., 1986; Henchoz and Kai-Lik So, 2008). For acute LBP,
${ }^{*}$ Corresponding author: Jad Adrian Washif (iD https://orcid.org/0000-0001-8543-4489 Sports Performance Division, National Sports Institute of Malaysia, National Sports Complex, Bukit Jalil, Kuala Lumpur 57000, Malaysia E-mail: jad@isn.gov.my

Received: October 23, 2018 / Accepted: January 9, 2019
This is an Open Access article distributed under the terms of the Creative Commons Attribution Non-Commercial License (http://creativecommons.org/licenses/by-nc/4.0/) which permits unrestricted non-commercial use, distribution, and reproduction in any medium, provided the original work is properly cited. 
immediate exercise is not recommended in order to avoid swelling of the affected area, and bed rest for 2 or 3 days could be more helpful (Deyo et al., 1986; Szpalski and Hayez, 1992). However, LBP may recede within 4-6 weeks with or without treatment (Hancock et al., 2008). Back pain is defined as chronic when the pain remains for longer than 3 months (Wells et al., 2014). Aerobic, core stabilisation, strength, and flexibility programme have been suggested as means to treat chronic LBP. Yet, the most appropriate treatment for LBP remains elusive (Gordon and Bloxham, 2016).

Although the cause of LBP is multifactorial, degeneration of the intervertebral discs has been linked to the triggering of LBP (Gordon and Bloxham, 2016; Luoma et al., 2000; Smith et al., 2011). The disc degeneration is characterised by tissue dehydration, that could weaken the inner (nucleus pulposus) and outer (annulus fibrosus) regions of the discs (Gordon and Bloxham, 2016; Smith et al., 2011). The weakening of the fibres may reduce their capacity to withstand a large compressive force. Consequently, the force distribution on the intervertebral discs is affected or transferred nonuniformly (Smith et al., 2011), altering the mechanical functions of the intervertebral discs in load distribution, energy dissipation, and joint mobility (Smith et al., 2011). The degenerative changes may result in lumbar instability, causing back pain from an uncontrolled motion (Parkhurst and Burnett, 1994). Hence, proper functioning (i.e., strong and organised) of the annulus fibrosus seems crucial for the spinal vertebrae (Gordon and Bloxham, 2016) and clarifies why an increase in lumbar instability is a possible reason for poor core strength. Therefore, strengthening and increasing proprioception to the core muscles may be essential (Cholewicki et al., 2005; Dreisinger, 2014; Inani and Selkar, 2013; Parkhurst and Burnett, 1994; Šarabon, 2011).

Recently, stochastic resonance therapy (SRT) has been used during rehabilitation programmes for normal and athletic populations. Stochastic resonance has potential to improve proprioceptive function (Collins et al., 2009) but paradoxically, decreased spine proprioception has been found in some cases of LBP patients (Reeves et al., 2009). Sensory information such as spine proprioception is essential for sensorimotor function as it can provide the body with a sense of position (e.g., sense of movement, force, and effort), that is also crucial for maintaining a stable spine (Reeves et al., 2009). Currently, there is increasing evidence regarding the usefulness of SRT for improving musculoskeletal function in patients with significant sensory deficits such as Parkinson disease (Haas et al., 2006; Kaut et al., 2011), and stroke (Priplata et al., 2006). SRT is also a well-accepted method to reduce the occur- rence musculoskeletal disorders in the neck, shoulders, LBP (Burger et al., 2012), and occupational musculoskeletal problems (Elfering et al., 2011). Therefore, this case study is presented to explore the feasibility and functionality of SRT as a means of treatment used in a rehabilitation programme for recurrent LBP in a resistance-trained individual.

\section{MATERIALS AND METHODS}

\section{Participants}

The male subject in this study was in his early thirties (basic information withheld), resistance-trained, and presented no history of serious LBP in the last 5 years, except an intermittent and nonspecific mild low-back discomfort, which did not require medical attention nor caused any psychological distress. He had been able to engage with general strength training 3 times a week for a duration of 45-90 min during each session and participated in various physical activities without any symptoms of LBP. Additionally, he has also recorded three repetitions of $110 \mathrm{~kg}$ during the power clean ( 1.4 times his bodyweight) a few weeks prior to his first complaint of LBP, attesting to his high fitness level. Relevant past medical history included acute LBP from sporting activities when he was 16 , which caused significant pain and physical limitation for almost a week. This episode recurred a year later.

The patient approached the rehabilitation centre and requested an appropriate rehabilitation programme to be arranged for him. He also requested that the interventions and results be published to help others who suffer the same predicament, and to enable further exploration of the LBP intervention used in the present study. Meanwhile, the treatment was conducted with the consent of the patient, following the principles outlined by the World Medical Assembly Declaration of Helsinki, and was carried out by a qualified sport therapist with over 20 years of experience. The patient's goals were to significantly reduce LBP, perform activities of daily living without restriction in movements, perform various strength exercises without an increase in pain, and reinitiate maximal strength exercise without pain.

\section{Instrumentation}

The outcome measures that were used included the Oswestry Disability Index (ODI) and an 11-point Numeric Rating Scale (NRS-11) for self-reporting of pain. The ODI has 10 items scored from 0 to 5 , and the overall score is expressed as a percentage, with higher scores indicating greater disability. A $50 \%$ pain reduction of the ODI has usually been considered successful. The NRS-11 is 
composed of an 11-point scale that is to be rated from 0 (no pain) to 10 (worst pain imaginable). A 2-point change on the rating scale was considered clinically meaningful. These subjective measures were completed in the morning before any physical activities took place. They were rated after simple flexion and extension movements (about 30-sec duration) of the trunk. In addition, strength and stabilisation tests were conducted using the bench press and plank exercises, respectively. During evaluation, the patient's history was taken and physical examination was carried out to determine functional restrictions, symptoms, risk factors, and neurological conditions.

\section{Chronological complaints First complaint}

The increased amount of work in his daily occupational roles in both sedentary office work (6-7 hr a day) and physical field work (3-4 hr a day) might have led to increased physical workloads. Having above average physical fitness, he was able to continue his active and intense lifestyle, which unfortunately could have led to increased tension in his body and lower back. The LBP flared up and was intolerable after he tried to rack a loaded barbell after performing a squat exercise (3 sets of 4-6 repetitions, $~ 1.8$ times of bodyweight). He tried to find the best position to relieve the back pain, and ended up lying down for almost an hour while applying ice therapy. His initial thought was that he had a muscle strain. Ice therapy was applied 3 times for a duration of 10-15 min each, with each application separated by $3 \mathrm{hr}$ during the first day, and three other applications were carried out the next day. $\mathrm{He}$ then arranged a clinical examination. The simple analgesics and nonsteroidal anti-inflammatory drugs (NSAIDs) provided by a physician did not seem very effective. This compelled him to seek further treatment after which he was given similar medications in addition to an injection to ease the pain. This procedure alleviated the discomfort about 10 days after the pain trigger from the strength training session. However, the episodes of acute pain did not completely dissipate.

\section{Second complaint}

Four weeks later, the pain occurred sporadically, ranging from 5 (distracting) to 8 (severe) on the NRS-11 during different times of the day. The sensation could be felt when standing or sitting for more than $10 \mathrm{~min}$, and during muscular activities that required lifting, or efforts that required higher intensity rated from 4 (moderate) to 5 (challenging) on the rating of perceived exertion (RPE) scale of 10. This stress from the pain started to interfere with his daily work and life quality. However, a review of his clinical examination did not yield any suspicion of serious spinal abnormality. He was given another injection to relieve the pain, and subsequently advised by a physician to enter a rehabilitation programme.

\section{Rehabilitation and strength training programme}

A rehabilitation programme was designed to meet the patient's goals. After the initial assessment by a physician, he met a sport therapist in order to be supervised closely throughout the rehabilitation period (Table 1, Fig. 1). The programme was divided into two phases with 3 weeks for phase 1 and 16 weeks for phase 2 . Phase 1 involved a protocol using several modalities including the SRT, relaxation and stabilisation exercises (Table 1), heat therapy, and musculoskeletal release. The general aims of this phase were to reduce the perceived LBP and to restore the functional limitations. SRT required the patient to be supine while on the SRT machine (SRT-Zeptoring Deutschland GmbH, Berlin Germany) that has two separate platforms which vibrate independently with

Table 1. Relaxation-stabilisation exercises and stochastic resonance therapy

\begin{tabular}{|c|c|c|c|}
\hline Exercise & Variables & Benefits & Descriptions \\
\hline Leg sway & $\begin{array}{l}1-2 \text { sets } \times 2 \text { min } \\
1-3 \text { weekly }\end{array}$ & $\begin{array}{l}\text { To promote a rapid symptom relief of lower } \\
\text { back. }\end{array}$ & $\begin{array}{l}\text { Sway the weighted leg gently and freely, forward and } \\
\text { backward. }\end{array}$ \\
\hline Pronated elbow extension & $\begin{array}{l}5-8 \text { sets } \times 8 \text { reps } \\
1-3 \text { weekly }\end{array}$ & To strengthen upper back and core. & $\begin{array}{l}\text { Extend and flex the elbows (hold a stick in wide grip) } \\
\text { in a controlled manner using a } 303 \text { tempo. }\end{array}$ \\
\hline Swiss ball oscillation & $\begin{array}{l}1-2 \text { sets } \times 2 \text { min } \\
1-3 \text { weekly }\end{array}$ & To promote relaxation to lower back & $\begin{array}{l}\text { Flat back against the floor or mat, both heels placed } \\
\text { on Swiss ball. } \\
\text { Oscillate the Swiss ball gently side-to-side. }\end{array}$ \\
\hline Isometric curl-up & $\begin{array}{l}4 \text { sets } \times 5 \text { reps ( } 5 \text { sec hold each) } \\
1-3 \text { weekly }\end{array}$ & Abdominal strength & $\begin{array}{l}\text { Flat back against the floor or mat. } \\
\text { Flex the body in a controlled manner, and return to the } \\
\text { initial position. }\end{array}$ \\
\hline Stochastic resonance therapy & $\begin{array}{l}4-5 \text { sets } \times 90 \text { sec, rest } 30 \mathrm{sec} \\
\text { (trim 2-3) }\end{array}$ & $\begin{array}{l}\text { Relaxation of back and increased } \\
\text { proprioception }\end{array}$ & $\begin{array}{l}\text { Flat back on the SRT machine, knee bent at } 90^{\circ} \text {, and } \\
\text { supported by a chair. }\end{array}$ \\
\hline
\end{tabular}



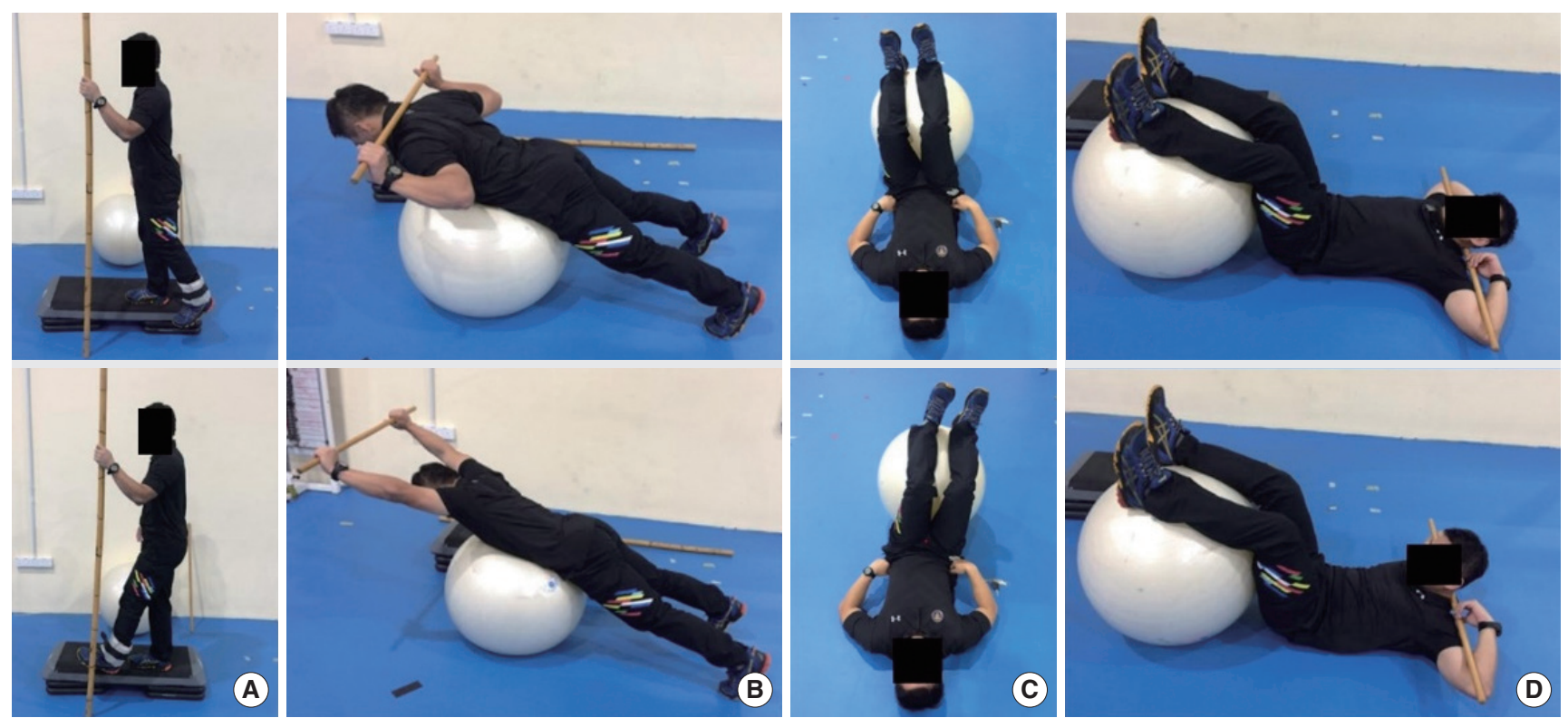

Fig. 1. Exercises performed during the rehabilitation program (presentation of this figure was approved by the patient). Leg sway (A), pronated elbow extension (B), swiss ball oscillation (C), and isometric curl-up (D).

a frequency between trim level 1 to 12 . Heat therapy was applied for $\sim 10$ min 2-3 times a week using hot packs or heated water. The musculoskeletal release was done using passive-assisted stretching exercises, and carried out two times during the first week of rehabilitation. Heavy weight-bearing exercises were not allowed during this period. Phase 2 involved a tailor-made strength training programme that aimed to restore the patient's normal lifestyle.

The tailor-made strength training was adhered to after seven sessions of the rehabilitation sessions. This included performing various free-weight and machine exercises that followed the principle of progressive overload (Table 2). Specific exercises for lumbar and core stabilisation were also included. In order to remain effective, challenging, and enjoyable, most of the training programme during week 5 and onwards was targeting at least two different neuromuscular characteristics (strength, hypertrophy, endurance) within the same session by manipulating the training variables (mixed periodisation). Of note, all sets were performed $1-2$ repetitions to failure to avoid risks or aggravation of LBP. The exercises in the programme was arranged orderly from easy to complex exercises. First, core activation was performed using specific strengthening exercises (10 repetitions $\times 2-3$ exercises). This was followed by a light warm up (3- to 5-min cycling or running, and 5- to 10-min dynamic movements) to further elevate overall body temperature to ensure muscular readiness. Subsequently, bodyweight, or/and the strength exercises were performed (Table
2). Taking into consideration the patient's goals and fitness background, a strength test was also conducted (bench press at relative loads of 1.0 and 1.2) after weeks 8 and 16 of phase 2. This type of testing was to identify the patient's strength level based on a specified benchmark over time. It is important to note that none of these exercises were performed under pain or tension, especially for the injured area. During the cool down session, static stretching was conducted for $1 \times 2$ sets of $10 \times 20 \mathrm{sec}$ for different muscles such as the hamstring, gluteus, and quadriceps.

\section{RESULTS}

The patient was observed during seven sessions in phase 1 of the rehabilitation period ( 3 weeks). The ODI was $66.7 \%$ prior to the first rehabilitation session, which can be interpreted as "crippling." The next tests of ODI were carried out after the fourth and seventh rehabilitation sessions and scores of $15.6 \%$ and $6.7 \%$ were achieved respectively. These ranges can be interpreted as "minimal." Meanwhile, the pain intensity of the NRS-11 ranged from 5 (distracting) to 9 (severe) prior to the first rehabilitation programme. LBP reduced considerably after two rehabilitation sessions (NRS-11 score: 4), and perceived normal after 4 sessions (NRS-11: 0 to 1). The scores of NRS-11 throughout phase 1 is shown in Fig. 2. From week 5 onwards, the patient performed various free-weight exercises without any restrictions. $\mathrm{He}$ accomplished the following tests during phase 2 without any complaints 
Table 2. General overview of tailor-made strength training programme

\begin{tabular}{|c|c|c|c|c|}
\hline Variable & Week 1-4 & Week 5-8 & Week 9-12 & Week 13-16 \\
\hline \multicolumn{5}{|l|}{ Basic exercises } \\
\hline Push up & $2-3 \times 20-30$ & - & - & - \\
\hline Squat & $2-3 \times 20-30$ & - & - & - \\
\hline Standing lunge & $2-3 \times 20-30$ & - & - & - \\
\hline Strength exercises & - & & & \\
\hline Bench press & $0.3-0.6 \mathrm{BW}$ & $0.5-0.7 \mathrm{BW}$ & $0.5-0.9 \mathrm{BW}$ & $0.5-1.1 \mathrm{BW}$ \\
\hline Overhead/push press & - & $20 \mathrm{~kg}$ & $20-40 \mathrm{~kg}$ & $30-50$ kg \\
\hline DB Bent-over row & - & $10-15 \mathrm{~kg}$ & $15-20 \mathrm{~kg}$ & $15-25 \mathrm{~kg}$ \\
\hline DB Hammer curl & - & $10-15 \mathrm{~kg}$ & $15-20 \mathrm{~kg}$ & $15-25 \mathrm{~kg}$ \\
\hline Leg press & - & 40-80 kg plates & 80-120 kg plates & 80-160 kg plates \\
\hline Hexagon deadlift & - & $0.5-0.7 \mathrm{BW}$ & $0.5-0.9 \mathrm{BW}$ & 0.5-1.1 BW \\
\hline Seated calf-raise & $0.3-0.6 \mathrm{BW}$ & $0.5-0.7 \mathrm{BW}$ & $0.5-0.9 \mathrm{BW}$ & $0.5-1.1 \mathrm{BW}$ \\
\hline \multicolumn{5}{|l|}{ Stabilisation exercises } \\
\hline Back extension without arms & BW & BW & BW & BW \\
\hline $45^{\circ}$ back extension & BW & BW & BW & BW \\
\hline Glute bridge & BW & BW & BW & BW \\
\hline Bird dog & BW & BW & BW & BW \\
\hline Cat and camel & BW & BW & BW & BW \\
\hline Plank (front/sides) & BW (30 sec) & BW (30-45 sec) & BW (30-60 sec) & BW (30-90 sec) \\
\hline Flutter kick & BW & BW & BW & BW \\
\hline Bridging & BW & BW & BW & BW \\
\hline Curl up & BW & BW & BW & BW \\
\hline Scissors & BW & BW & BW & BW \\
\hline
\end{tabular}

BW, bodyweight; DB, dumbbell.

Number of exercise $=2$ BW exercises, 2-4 strength exercises, and 2-4 stabilisation exercises during each session. Exercise frequency $=2-3$ times weekly on nonconsecutive days. Number of set $=2-3$ sets during each session. Number of repetitions $=3-15$ repetitions for strength exercises (endurance: $1 \times 12-15$, hypertrophy: $1 \times 8-12$, strength: $1 \times 3-6)$ and $10-20$ repetitions for stabilisation exercises. Tempo = moderate. General training objectives $=$ to execute exercises with a sound biomechanical technique and to develop general strength.

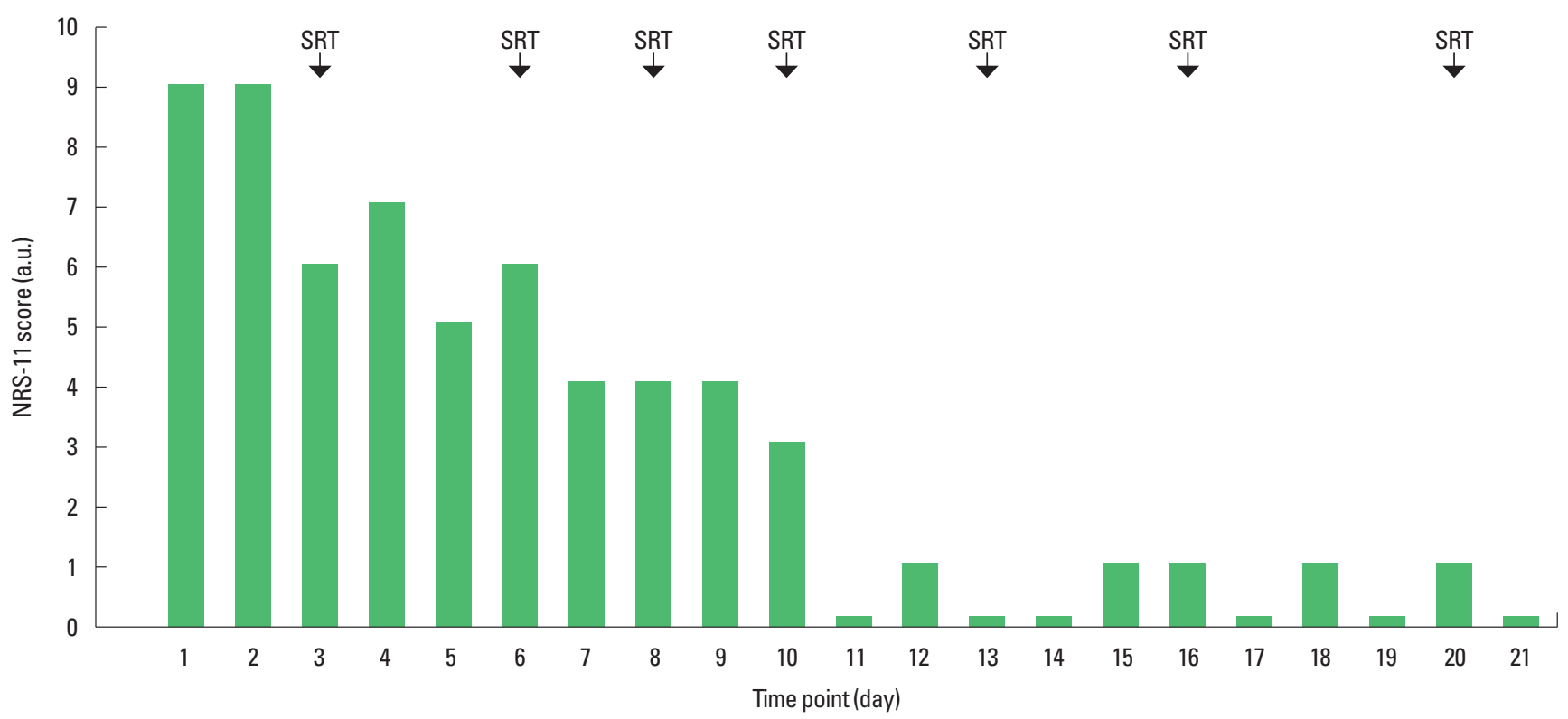

Fig. 2. Numeric rating scale (NRS) for pain intensity and stochastic resonance therapy (SRT) intervention throughout the 3-week rehabilitation programme. 
of pain or discomfort: (a) three repetitions at a load intensity equal to his bodyweight during bench press at week 8; (b) two repetitions at a load intensity of 1.2 his bodyweight during bench press at week 16; (c) 4-min plank stabilisation at week 16 . However, it is also important to note that he occasionally felt mild discomfort at the lower-back resulted during occupational activities at some points of this period, which required minor adjustments to his body posture for the pain or discomfort to disappear.

\section{DISCUSSION}

This case study describes the use of SRT and strength training for LBP management. The primary finding suggests that the rehabilitation programme has a clinically meaningful effect on pain intensity and disability reduction, while restoring functional mobility. It is important to highlight that there was a $51 \%$ reduction in pain and disability as assessed via the ODI after the 4th rehabilitation session, and a further $\sim 8 \%$ reduction after 7 th session, accumulating approximately $60 \%$ improvement in functional mobility and lifestyle after 3 weeks of the rehabilitation programme. A similar trend of changes was observed for the numeric rating scale. The lowest recorded pain intensity before the first SRT was 6 , and from day 11 (after 4 SRT), the pain intensity seemed to stabilise at a low level (i.e., $0-1$ ), that is reduction of $\sim 5$ points, which was considered meaningful. Meanwhile, the tailor-made strength programme that was commenced subsequently seems capable of averting the recurrence of LBP, while helping the patient to accomplish his goals during the period of observation. He performed various physical activities including strength exercises that were done without functional limitations and pain, and also reinitiated a maximal strength exercise (bench press) successfully without pain. With regards to pain reduction, a considerable symptom improvement after only 1 week was not totally unexpected as the patient was on a course of NSAIDs and he had also spent more time resting. Furthermore, the low frequency vibration during SRT may have provided muscle relaxation effects. Collectively, these factors could have facilitated the reduction of LBP.

A potentially favourable outcome of using the SRT was discussed extensively in the literature. Briefly, as the vibration is stochastic, it provides a randomised noise, in which the direction and the force-time behaviour of the vibrations are not foreseeable (unpredictable) and the body will be constantly challenged to adapt muscle reactions (Elfering et al., 2011; Haas et al., 2006). Also, SR is based on the principles that low-level noise sensitizes the sensory systems in a way that reduces the stimulus threshold
(Reeves et al., 2009). In other words, a stochastic stimulus can facilitate a higher detection sensitivity. Therefore, noise that is added in optimal amounts may have enhanced information transfer and subsequently improved the detection of subthreshold signals (Itzcovich et al., 2017). In the present study, SRT was given throughout phase 1 although after the patient has been feeling well (Fig. 2) in order to provide a means of improving sensory proprioception. However, when previous literature was examined, there were mixed outcomes regarding the efficacy of vibration for LBP treatment. Some research supported its use, while more recent ones questioned its effectiveness and safety (Perraton et al., 2011) especially with regards to the aetiological factor of LBP from occupations that require individuals to be in the sitting position while working with machinery that vibrated repeatedly (Perraton et al., 2011). In addition to this, a recent review supported that exposure to whole-body vibrations elevated the risk of LBP and sciatica (Burström et al., 2015), suggesting that body position during the treatment of LBP using vibrations needed reconsideration. Unlike whole-body vibration that requires treatment to be done mostly in a standing position, the present study applied the vibration directly to the intended muscles. Here, the SRT was arranged so that the patient would undergo treatment in a supine body position (lying bent-knee with heels on a chair), which in turn, could have promoted better relaxation of muscles while preserving the spinal cord during the treatment.

As LBP development is related to the degeneration of intervertebral discs (Luoma et al., 2000), a higher risk of tissue strain may occur as a result of decreased proprioception that could reduce the control of forces created through the lumbar spine, especially from an uncontrolled motion. Further to this point, some individuals with back problems are classified as having soft tissue injury, in which the receptors embedded in the spinal soft tissue (such as ligaments, facet joints, intervertebral discs, and paraspinal muscle) could be damaged, which reduce the quality of sensory reception in the spine (Reeves et al., 2009). Consequently, the role of proprioception in maintaining dynamic lumbar stability is essential (Cholewicki et al., 2005; Parkhurst and Burnett, 1994). Apart from improving proprioception with SRT, strengthening exercises seemed beneficial for the intervention and management of LBP (Cholewicki et al., 2005; Dreisinger, 2014; Inani and Selkar, 2013; Jackson et al., 2011; Parkhurst and Burnett, 1994; Šarabon, 2011; Welch et al., 2015) to promote better stability of the lumbar. Moreover, increasing fitness level using strength training is necessary in order to prevent deconditioning of musculoskeletal system that was suggested to be associated with chronic LBP (Kell 
and Asmundson, 2009), which could also be a reason for the LBP reoccurrence of the patient in the present study.

Strength training has been recommended by the American College of Sports Medicine (ACSM) for various health and performance benefits (American College of Sports Medicine, 2009). Different types of strengthening exercises were used as part of a strategy for restoring muscle functions while improving stability of the lumbar spine (Mayer et al., 2003). In previous literature, stabilisation exercises (Dreisinger, 2014; Inani and Selkar, 2013; Šarabon, 2011) were more widely used than the free-weight exercises (Jackson et al., 2011; Welch et al., 2015), although freeweight exercises are safe and yielded positive results (Jackson et al., 2011; Welch et al., 2015). This practice was in accordance with earlier studies showing effectiveness of stabilisation exercises for LBP management (Inani and Selkar, 2013; Šarabon, 2011). For example, a 3-month intervention that incorporated exercises such as the slow curl-up, bird dog, the plank and sit-ups, obtained a higher reduction of LBP (76.8\%) when compared to a group $(62.8 \%)$ that used conventional spine exercises such as static stretching (Inani and Selkar, 2013).

The programme with free-weight exercises for LBP intervention may be employed based on the types of LBP and the timing of treatment application for better outcomes. Yet, it was difficult to determine which rehabilitation programme is better among the various modalities that examined the effects of exercise on LBP because different methodologies and tests were used. In the present study, phase 1 included exercises to improve the deep core muscles (stabilisation) to better prepare the body for the exercises performed during phase 2 that required greater intensity of muscles contraction. This approach might have addressed the limitations in the previous exercise rehabilitation studies, which did not sufficiently stress the large muscle groups to enhance the overall health of the musculoskeletal system (Kell and Asmundson, 2009). Therefore, the results in the present study endorsed the appropriate use of strength training in a resistance-trained individu$\mathrm{al}$, confirming the notion that resistance training is more efficient when compared to other strategies used for LBP management (Dreisinger, 2014). Indirect support was also obtained from a study that reported patients who restricted their trunk movement with a goal of reducing the pain, may have actually weakened his/ her core strength and lumbar stability, which in turn prolonged the LBP (Danneels et al., 2000). Therefore, the results from the current study is comparable to the current consensus from literature proposes that a rehabilitation programme which combines strength and stabilisation exercises seems more effective if pre- scribed appropriately (Jackson et al., 2011; Kell and Asmundson, 2009; Stankovic et al., 2012).

Nonetheless, this case study is not without limitations. Ultrasound imaging or MRI might have been more accurate for assessing the severity of LBP. However, these objective measurements require additional devices that are often not readily available. Even though the results from a single subject may not be effectively generalised, it was also important to identify the specific exercises which are suitable and effective for an individual (as in this case study), as opposed to exercise prescriptions for a generic group since the major goal of the rehabilitation programme was returning the patient to an active lifestyle.

The primary outcomes of this case study demonstrated that a 3-week rehabilitation programme incorporating SRT and specific exercises was effective to reduce pain intensity and disability in a strength-trained patient with LBP. The tailor-made strength training enabled the patient to remain active and be able to perform various activities without movement restrictions, while potentially preventing the recurrence of LBP. Collectively, the intervention used in the present study has clinically meaningful effects on pain intensity, disability, and functional mobility. However, further studies are needed to better understand the current findings and its mechanisms.

\section{CONFLICT OF INTEREST}

No potential conflict of interest relevant to this article was reported.

\section{REFERENCES}

Allegri M, Montella S, Salici F, Valente A, Marchesini M, Compagnone C, Baciarello M, Manferdini ME, Fanelli G. Mechanisms of low back pain: a guide for diagnosis and therapy. Version 2. F1000Res. 2016 Jun 28 [revised 2016 Oct 11];5. pii: F1000 Faculty Rev-1530. eCollection 2016.

American College of Sports Medicine. American College of Sports Medicine position stand. Progression models in resistance training for healthy adults. Med Sci Sports Exerc 2009;41:687-708.

Burger C, Schade V, Lindner C, Radlinger L, Elfering A. Stochastic resonance training reduces musculoskeletal symptoms in metal manufacturing workers: a controlled preventive intervention study. Work 2012;42:269-278.

Burström L, Nilsson T, Wahlström J. Whole-body vibration and the risk of low back pain and sciatica: a systematic review and meta-analysis. Int Arch Occup Environ Health 2015;88:403-418. 
Cholewicki J, Silfies SP, Shah RA, Greene HS, Reeves NP, Alvi K, Goldberg B. Delayed trunk muscle reflex responses increase the risk of low back injuries. Spine (Phila Pa 1976) 2005;30:2614-2620.

Collins AT, Blackburn JT, Olcott CW, Dirschl DR, Weinhold PS. The effects of stochastic resonance electrical stimulation and neoprene sleeve on knee proprioception. J Orthop Surg Res 2009;4:3.

Danneels LA, Vanderstraeten GG, Cambier DC, Witvrouw EE, De Cuyper HJ. CT imaging of trunk muscles in chronic low back pain patients and healthy control subjects. Eur Spine J 2000;9:266-272.

Deyo RA, Diehl AK, Rosenthal M. How many days of bed rest for acute low back pain? A randomized clinical trial. N Engl J Med 1986;315: 1064-1070.

Dreisinger TE. Exercise in the management of chronic back pain. Ochsner J 2014;14:101-107.

Elfering A, Thomann J, Schade V, Radlinger L. Stochastic resonance whole body vibration reduces musculoskeletal pain: a randomized controlled trial. World J Orthop 2011;2:116-120.

Gordon R, Bloxham S. A Systematic Review of the Effects of Exercise and Physical Activity on Non-Specific Chronic Low Back Pain. Healthcare (Basel) 2016;4(2):22.

Haas CT, Turbanski S, Kessler K, Schmidtbleicher D. The effects of random whole-body-vibration on motor symptoms in Parkinson's disease. NeuroRehabilitation 2006;21:29-36.

Hancock MJ, Maher CG, Latimer J. Spinal manipulative therapy for acute low back pain: a clinical perspective. J Man Manip Ther 2008;16:198203.

Henchoz Y, Kai-Lik So A. Exercise and nonspecific low back pain: a literature review. Joint Bone Spine 2008;75:533-539.

Hoy D, Brooks P, Blyth F, Buchbinder R. The Epidemiology of low back pain. Best Pract Res Clin Rheumatol 2010;24:769-781.

Hoy D, March L, Brooks P, Blyth F, Woolf A, Bain C, Williams G, Smith E, Vos T, Barendregt J, Murray C, Burstein R, Buchbinder R. The global burden of low back pain: estimates from the Global Burden of Disease 2010 study. Ann Rheum Dis 2014;73:968-974.

Inani SB, Selkar SP. Effect of core stabilization exercises versus conventional exercises on pain and functional status in patients with non-specific low back pain: a randomized clinical trial. J Back Musculoskelet Rehabil 2013;26:37-43.

Itzcovich E, Riani M, Sannita WG. Stochastic resonance improves vision in the severely impaired. Sci Rep 2017;7:12840.

Jackson JK, Shepherd TR, Kell RT. The influence of periodized resistance training on recreationally active males with chronic nonspecific low back pain. J Strength Cond Res 2011;25:242-251.

Kaut O, Allert N, Coch C, Paus S, Grzeska A, Minnerop M, Wüllner U. Stochastic resonance therapy in Parkinson's disease. NeuroRehabilita- tion 2011;28:353-358.

Kell RT, Asmundson GJ. A comparison of two forms of periodized exercise rehabilitation programs in the management of chronic nonspecific low-back pain. J Strength Cond Res 2009;23:513-523.

Koes BW, van Tulder MW, Thomas S. Diagnosis and treatment of low back pain. BMJ 2006;332:1430-1434.

Lidgren L. The bone and joint decade 2000-2010. Bull World Health Organ 2003;81:629.

Luoma K, Riihimäki H, Luukkonen R, Raininko R, Viikari-Juntura E, Lamminen A. Low back pain in relation to lumbar disc degeneration. Spine (Phila Pa 1976) 2000;25:487-492.

Mayer JM, Udermann BE, Graves JE, Ploutz-Snyder LL. Effect of Roman chair exercise training on the development of lumbar extension strength. J Strength Cond Res 2003;17:356-361.

Parkhurst TM, Burnett CN. Injury and proprioception in the lower back. J Orthop Sports Phys Ther 1994;19:282-295.

Perraton L, Machotka Z, Kumar S. Whole-body vibration to treat low back pain: fact or fad? Physiother Can 2011;63:88-93.

Petering RC, Webb C. Treatment options for low back pain in athletes. Sports Health 2011;3:550-555.

Priplata AA, Patritti BL, Niemi JB, Hughes R, Gravelle DC, Lipsitz LA, Veves A, Stein J, Bonato P, Collins JJ. Noise-enhanced balance control in patients with diabetes and patients with stroke. Ann Neurol 2006; 59:4-12.

Reeves NP, Cholewicki J, Lee AS, Mysliwiec LW. The effects of stochastic resonance stimulation on spine proprioception and postural control in chronic low back pain patients. Spine (Phila Pa 1976) 2009;34:316321.

Šarabon N. Effects of trunk functional stability training in subjects suffering from chronic low back pain: a pilot study. Kinesiol Slov 2011;17: 25-37.

Smith LJ, Nerurkar NL, Choi KS, Harfe BD, Elliott DM. Degeneration and regeneration of the intervertebral disc: lessons from development. Dis Model Mech 2011;4:31-41.

Stankovic A, Lazovic M, Kocic M, Dimitrijevic L, Stankovic I, Zlatavovic D. Lumbar stabilization exercises in addition to strengthening and stretching exercises reduce pain and increase function in patients with chronic low back pain: randomized clinical open-label study. Turk J Phys Med Rehab 2012;58:177-183.

Szpalski M, Hayez JP. How many days of bed rest for acute low back pain? Objective assessment of trunk function. Eur Spine J 1992;1:29-31.

Welch N, Moran K, Antony J, Richter C, Marshall B, Coyle J, Falvey E, Franklyn-Miller A. The effects of a free-weight-based resistance training intervention on pain, squat biomechanics and MRI-defined lumbar fat infiltration and functional cross-sectional area in those with 
chronic low back. BMJ Open Sport Exerc Med 2015;1:e000050.

Wells C, Kolt GS, Marshall P, Bialocerkowski A. The definition and application of Pilates exercise to treat people with chronic low back pain: a
Delphi survey of Australian physical therapists. Phys Ther 2014;94: 792-805. 